\title{
Control model design to limit DC-link voltage during grid fault in a dfig variable speed wind turbine
}

\author{
Cajethan M. Nwosu, Cosmas U. Ogbuka, Stephen E. Oti ${ }^{*}$
}

\begin{abstract}
This paper presents a control model design capable of inhibiting the phenomenal rise in the DC-link voltage during gridfault condition in a variable speed wind turbine. Against the use of power circuit protection strategies with inherent limitations in fault ride-through capability, a control circuit algorithm capable of limiting the DC-link voltage rise which in turn bears dynamics that has direct influence on the characteristics of the rotor voltage especially during grid faults is here proposed. The model results so obtained compare favorably with the simulation results as obtained in a MATLAB/SIMULINK environment. The generated model may therefore be used to predict near accurately the nature of DC-link voltage variations during fault given some factors which include speed and speed mode of operation, the value of damping resistor relative to half the product of inner loop current control bandwidth and the filter inductance.
\end{abstract}

K e y w or d s: active damping, DC-link voltage, virtual resistor, control loop bandwidth

\section{Introduction}

Filters have widely been used as essential component of grid-connected voltage source converters to attenuate the high frequency ripple currents due to switching harmonics. In terms of better harmonics attenuation and fast dynamic response, the popularity of the filters advances from the first-order single inductive (L) filter [1], through second-order inductive-capacitive (LC) filter [14] to third-order inductive-capacitive-inductive (LCL) filter $[1,5-12]$. When the operating condition of any of the filter topology is suddenly changed, a large transient oscillation can be generated in the filter. This condition is even more worrisome in the higher-order filters especially the LCL filters. In addition to the transient oscillations, the LCL filter also may lead to the amplification of undesired harmonic components around the closed loop stability boundary due to the presence of a pole pair at the resonant frequency $[13,14]$.

Because the resistances of the filters are usually very low, the oscillation is only slightly damped and may continue to oscillate [15]. Under this condition, the source current will be badly distorted. The damping of the oscillations can be realized either passively or actively. In addition to modifying the transfer function and degrading of harmonic suppression capability of the filters, passive damping methods create a considerable amount of power loss especially in high power applications $[14,16]$. Because of excessive power loss in the resistor, this method is impractical especially in high-power applications [2].

On the other hand, active damping entails modifying the control algorithm by adding a virtual resistor in place of the real resistor to make the filter behave as if a real resistor is added to it $[3,17]$. The virtual resistor entails placing additional control loop alongside the current control loop. In addition to eliminating excessive power loss in the resistor, active damping methods could be used for low and medium power applications [16]. Because no real resistor is used, the transient oscillations can be damped without sacrificing the efficiency. Active damping can also be achieved in various ways. These include but not limited to cascading digital filters in series with the current controllers [18], feeding back additional filter variables [19], adding lead-lag compensator into the current control loop [20,21], genetic algorithm (GA) to adapt an active damping [22], etc.

The benefits of the dynamics of active damping criteria is in this paper utilized to model a control design in order to limit the phenomenal rise in the DC-link voltage during grid faults with the first-order inductive filter. A virtual resistor $R_{D}$ in series with the input filter $L_{f}$, in a grid-side PWM converter scheme is represented in Fig. 1. $v_{a}, v_{b}, v_{c}$ and $i_{a}, i_{b}, i_{c}$ are the grid voltages and currents respectively, $v_{a 1}, v_{b 1}, v_{c 1}$ are the frontend converter voltages, $i_{\mathrm{DCg}}$ and $i_{\mathrm{DCr}}$ are the grid-side converter DC-link current and rotor-side converter DClink current respectively, $v_{\mathrm{DC}}$ is the DC-link current.

Perhaps, one striking benefit of the application of this algorithm to the control of DC-link voltage during grid fault condition is that, in addition to damping the highfrequency ripple due to switching harmonics and the resulting oscillations, appropriate selection of $R_{D}$ in relation to the inner current control loop bandwidth can lead to keeping the DC-link voltage constant even as the fault lasts.

Department of Electrical Engineering, University of Nigeria, Nsukka, Nigeria, cajethan.nwosu@unn.edu.ng, cosmas.ogbuka@unn.edu.ng, stephen.oti@unn.edu.ng 


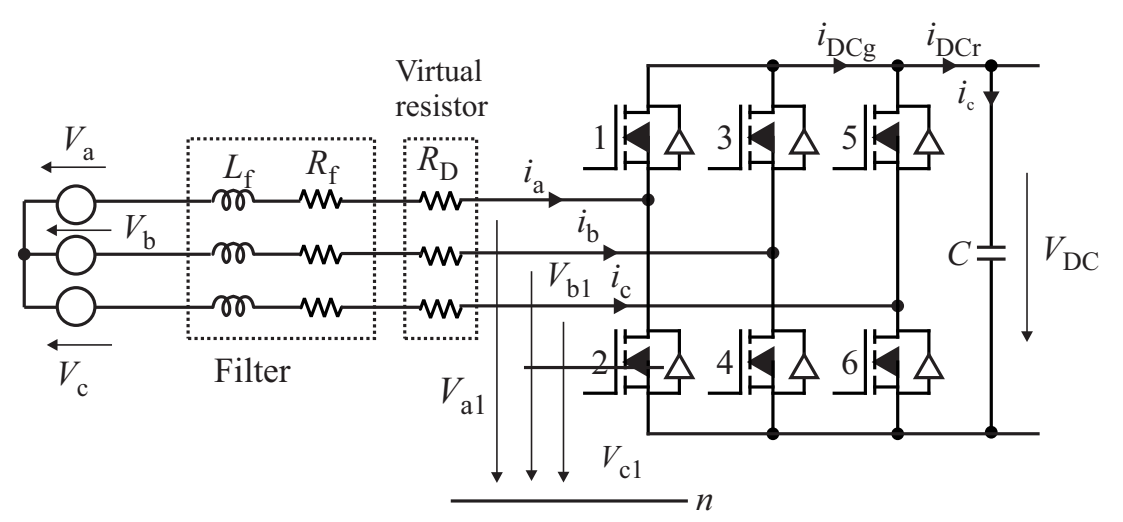

Fig. 1. Grid - side PWM converter scheme

Figure 2 shows a single line diagram representation of one phase of the input system where $v_{s}, i_{L}, i_{\text {in }}$, and $v_{\mathrm{o}}$ represent the source voltage, inductor filter current, converter input current, and converter input voltage respectively. The converter input voltage may be regarded as a disturbance; the disturbance can effectively be damped with proper selection of $R_{D}$ value. Here, it is assumed that the filter current is controlled using a classical PI controller.

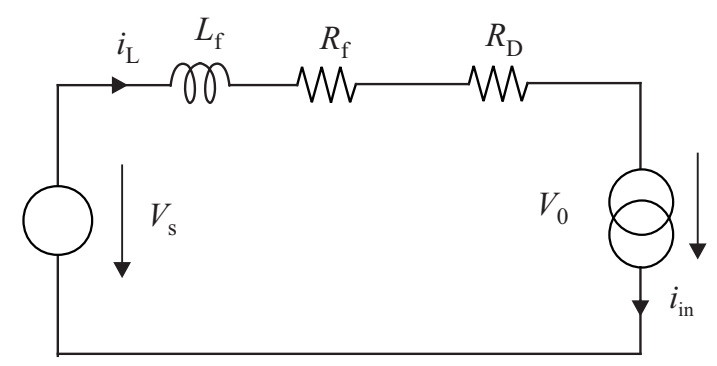

Fig. 2. One phase of the filter interface

Shown in Fig. 3 is the block diagram representation of the control algorithm. The $R_{D}$ in Fig. 3 known as a virtual resistor because it is not really connected in series with the filter performs the active damping in this control algorithm. As it is shown by the block diagram, the role of $R_{D}$ is to reduce the voltage across the inductor by a voltage that is proportional to the current through it.

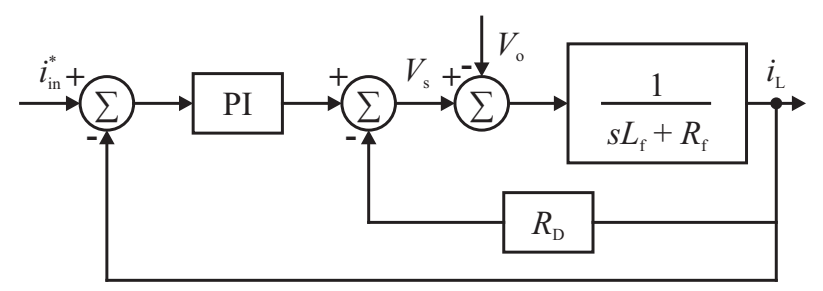

Fig. 3. Control block algorithm

\section{Modeling of control strategy}

In Laplace domain, a model of Fig. 2, (although $R_{D}$ is in practice not connected to the filter), is given by

$$
v_{s}(s)-v_{o}(s)=\left(s L_{f}+R_{f}+R_{D}\right) i_{L} .
$$

For the control block diagram of Fig. 3, the following equation can be deduced

$$
v_{s}(s)-v_{0}(s)=\left[k_{P}+\frac{k_{I}}{s}\right]\left[i_{\text {in }}^{*}-i_{L}\right]-i_{L} R_{D} .
$$

The transformed dq voltages across the filter rotating at the grid frequency $\omega_{e}[15]$, with the d-axis of the reference frame aligned to the grid voltage vector and dropping the subscript ' $f$ ' are

$$
\begin{aligned}
& v_{d}=R i_{d}+L s i_{d}-\omega_{e} L i_{q}+v_{d 1} \\
& v_{q}=R i_{q}+L s i_{q}+\omega_{e} L i_{d} .
\end{aligned}
$$

The introduction of $R_{D}$ changes the d-axis and q-axis current control laws to

$$
\begin{gathered}
v_{d}^{*}=-\left(v_{d}^{\prime}-R_{D} i_{d}\right)+\left(\omega_{e} L i_{q}+v_{d}\right), \\
v_{q}^{*}=-\left(v_{q}^{\prime}-R_{D} i_{q}\right)-\left(\omega_{e} L i_{d}\right), \\
v_{d}^{\prime}=\left(k_{p d}+\frac{k_{i d}}{s}\right)\left(i_{d}^{\mathrm{ref}}-i_{d}\right) \\
v_{q}^{\prime}=\left(k_{p q}+\frac{k_{i q}}{s}\right)\left(i_{q}^{\mathrm{ref}}-i_{q}\right) .
\end{gathered}
$$

The inner closed-loop transfer function, assuming ideal parameters, becomes

$$
G_{d q}(s)=\frac{i_{d q}(s)}{v_{d q}(s)}=\frac{1}{s L+R+R_{D}} .
$$

Then, by utilizing Internal Model Control (IMC) [23] and taking into consideration the converter constant $k_{c}$, the following PI controller for the $\mathrm{d}$ and $\mathrm{q}$ frames is obtained

$$
C(s)=\frac{\alpha}{s}\left(k_{c} G_{d q}\right)^{-1}(s)=\frac{\alpha L}{k_{c}}+\frac{\alpha\left(R+R_{D}\right)}{s k_{c}},
$$

where $\alpha$ stands for the inner current control loop bandwidth. The active damping may be chosen as $R_{D}=$ 
(a)

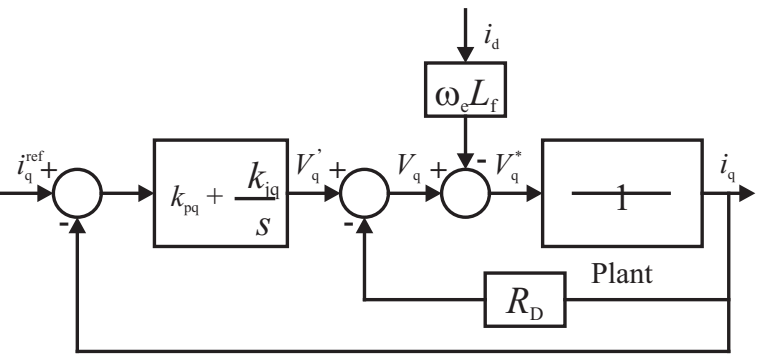

(b)

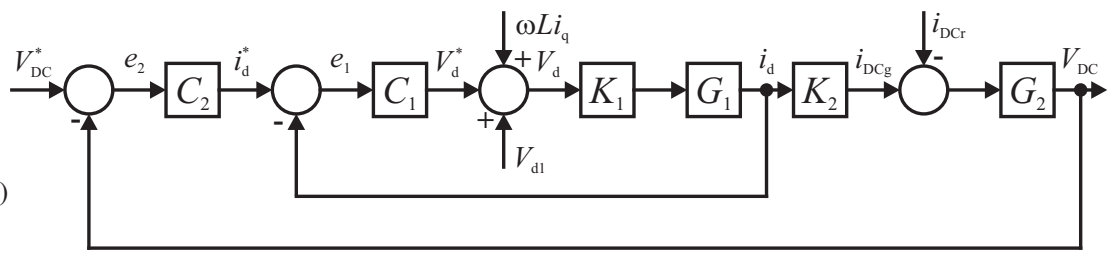

(c)

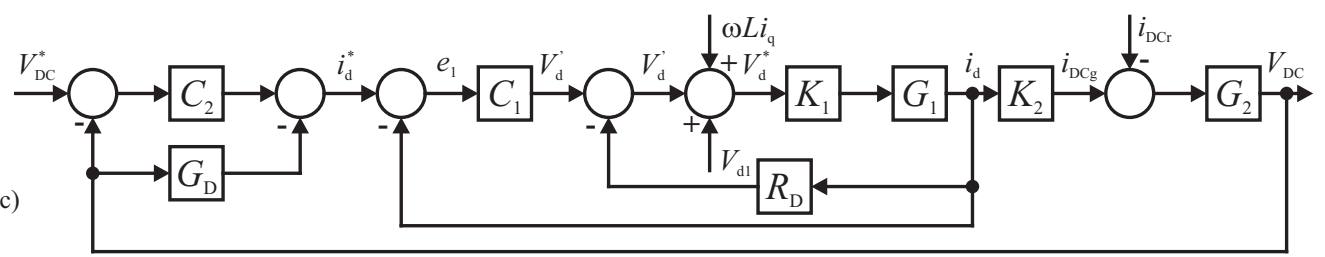

Fig. 4. (a) - block diagram of the current control of the q-axis reference frame with active damping, and the complete control structure for the outer DC-link voltage and the inner current control, (b) - without, and (c) — with voltage or current damping

$\alpha_{d q} L-R$ [24]. The dq-axis current control law can be written as

$$
\begin{aligned}
& v_{d}=\left(k_{p d}+\frac{k_{i d}}{s}\right)\left(i_{d}^{\mathrm{ref}}-i_{d}\right)-R_{D} i_{d} \\
& v_{q}=\left(k_{p q}+\frac{k_{i q}}{s}\right)\left(i_{q}^{\mathrm{ref}}-i_{q}\right)-R_{D} i_{q} .
\end{aligned}
$$

The gains are

$$
k_{p d q}=\frac{\alpha_{d q} L}{k_{c}}, \quad k_{i d q}=\frac{\alpha_{d q}\left(R+R_{D}\right)}{k_{c}} .
$$

The addition of active damping manifests only in the integral control parameter with an effect to eliminate offset through integral action and remove the steady state error in satisfactory time, in-so-far-as the reference signal is constant. The block diagram of the current control of the q-axis (without the converter model) is shown in Fig. 4a with the active damping added.

The complete control structure incorporating the outer DC-link voltage control and the inner current control without active damping and with active damping are shown in Figs. 4b and 4c respectively. From each of the complete control structures, the cross-coupling (or rotational) voltage $\omega$ Liq resulting from the d-q transformations, and the d-component of the line voltage $v_{d 1}$ are fed-forward while the rotor-side DC-link current $i_{D C r}$ is regarded as disturbance and one of the aims of the damping control strategy in Fig. 4(c) is to have the disturbance damped.

In Figs. $4 \mathrm{~b}$ and c, $C_{1}$ and $C_{2}$ are the PI controllers for the inner current control and outer DC-link voltage control, $K_{1}$ and $K_{2}$ are the grid-side converter (GSC) control constants for the inner current and outer DC-link voltage, $G_{1}$ and $G_{2}$ are the plants for the current control and DC-link voltage control.

\section{DC-link voltage variation during fault condition}

It has been established that for active damping, $R_{D}=$ $\alpha_{d q} L-R$ may be chosen. If we neglect the line resistance $\mathrm{R}$ since its contribution to the value of RD is infinitesimal, the active resistance may be approximated by $R_{D}=\alpha L$ . The subscript dq is dropped owing to symmetry in the dq axes of the inner current control loops.

The instantaneous DC-Link voltage within the fault period for sub-synchronous and super-synchronous modes of operations may be modeled using the equation

$$
v_{D C f}(t)=\left\{\begin{array}{l}
K_{s u b} v_{D C}+k_{1} v_{D C}\left(1-e^{-b t}\right), \\
K_{s u b} v_{D C}+k_{2} v_{D C}\left(e^{-b t}-1\right), \\
K_{\mathrm{sup}} v_{D C}+k_{1} v_{D C}\left(1-e^{-b t}\right), \\
K_{\mathrm{sup}} v_{D C}+k_{2} v_{D C}\left(e^{-b t}-1\right),
\end{array}\right.
$$

where $v_{D C f}(t)$ is the instantaneous DC-link voltage within the fault period, $v_{D C}$ is the nominal DC-link voltage, $K_{\text {sub }}$ and $K_{\text {sup }}$ are sub-synchronous and supersynchronous factors whose values at the inception of fault condition depend on speed and speed mode of operation, $k_{1}$ and $k_{2}$ are the factors that determine the instantaneous magnitudes of the DC-link voltage within the fault 


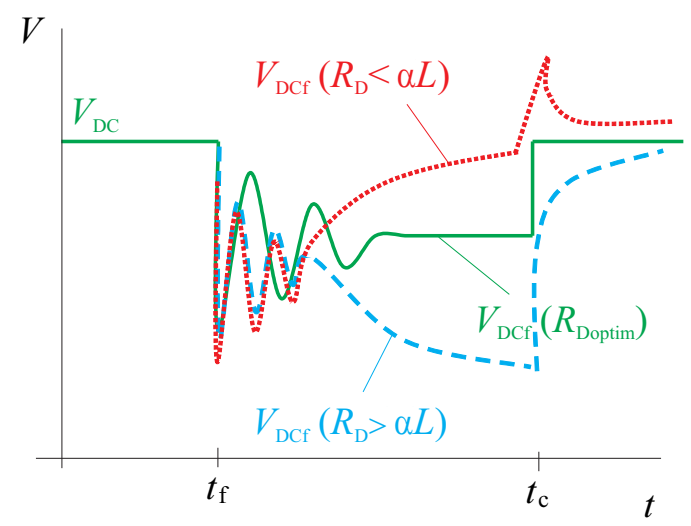

Fig. 5. DC-link voltage variation during fault

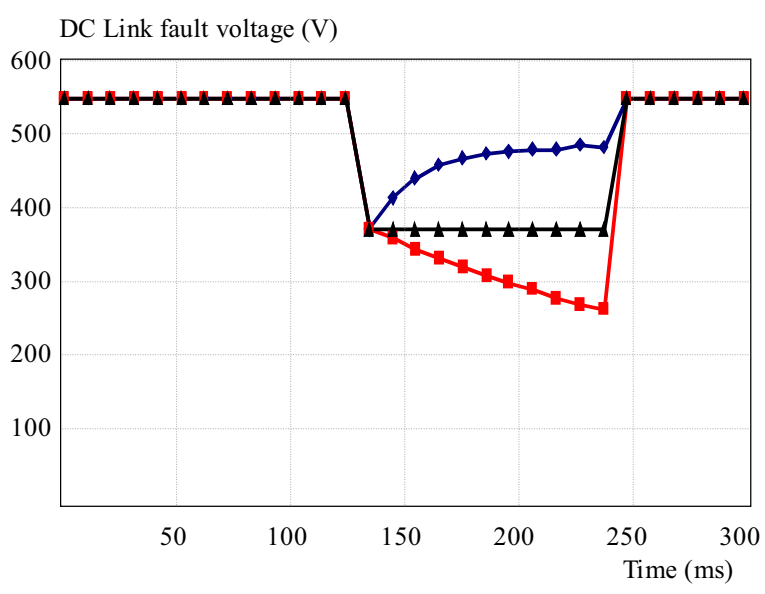

Fig. 6. Approximate model of DC-link fault voltage during subsynchronous speed mode

duration. Their values depend on the value of $R_{D}$ relative to the factor $\alpha L / 2$; they may assume definite values for the ranges of $R_{D} \geq \alpha L / 2$ while their values increase for the ranges of $R_{D} \leq \alpha L / 2$ especially as it applies to (14) and (16). The parameter $b$, for this model varies in the range $1 l e b \leq 10$ for (14) and (16) and in the range $0.1 \leq b \leq 1.0$ for $(15)$ and (17).

For any value of $R_{D}$ at which $K_{\text {sub }}$ or $K_{\text {sup }}$ is maintained constant through the duration of the fault, the parameter $b$ is zero. Equations (14) and (15) are for sub-synchronous speed while (16) and (17) are for supersynchronous speed modes of operations. At $R_{D}=R_{\text {Dopt }}$ corresponding to $b=0$, the second factor at the right hand side (R.H.S.) of (14) to (17) become zero. At this instant, the function ' $t$ ' in seconds seizes to have any effect on the DC-Link fault voltage and (14) and (15) give same result while (16) and (17) give same result. Figure 5 shows the variation of the DC-link voltage during fault condition as the damping resistance varies. At lower values of $R_{D}$ the $v_{D C f}$ grows exponentially within the fault duration while at higher values of $R_{D}$ it decays also exponentially. $t_{f}$ is the time of fault occurrence, and $t_{c}$ is the time of fault clearance. Using the approximate model (14) and (15), Fig. 6 is generated each for $R_{D}=R_{\text {Dopt }}$,

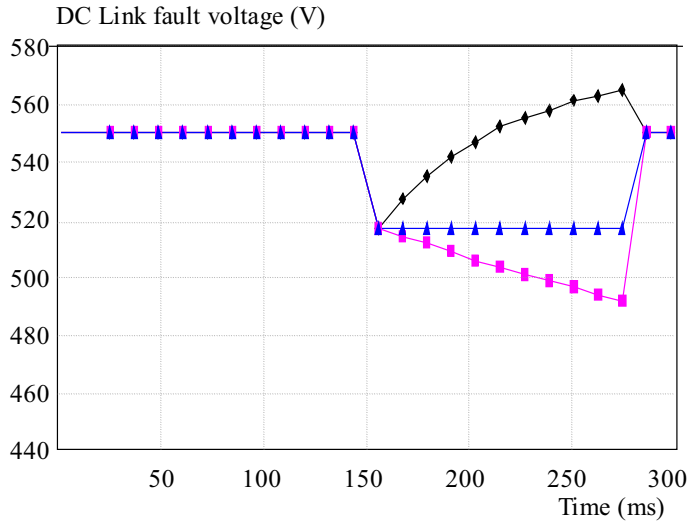

Fig. 7. Approximate model of DC-link fault voltage during supersynchronous speed mode

$R_{D}<\alpha L$ and $R_{D}>\alpha L$. The factor $\alpha L$ has been defined as the product of the control loop bandwidth and the filter inductance which in this case is 27. For Fig. 6, $K_{\text {sub }}$ of 0.68 corresponding to the sub-synchronous speed of $\left(\omega_{s}-0.3 \omega_{s}\right)$ is used, $b=5$ is used in (14) while $b=0.5$ is used in (15). Also for Fig. $6, k_{1}=0.2$, and $k_{2}=0.5$ are used.

Using (16) and (17), Fig. 7 is generated each for $R_{D}=$ $R_{\text {Dopt }}, R_{D}<\alpha L$ and $R_{D}>\alpha L$. For Fig. $7, K_{\text {sup }}$ of 0.94 corresponding to the super-synchronous speed of $\left(\omega_{s}+0.3 \omega_{s}\right)$ is used, $b=2$ is used in (16) while $b=0.2$ is used in (17). Also for Fig. 7, $k_{1}=0.1$, and $k_{2}=0.25$ are used.

\section{Simulation results}

The DC-link voltage variation during fault condition for various values of $R_{D}<\alpha L / 2$ and $R_{D}>\alpha L / 2$ is simulated on the MATLAB/SIMULINK platform. Figure 8 shows different simulation results for different values of $R_{D}$ for sub-synchronous speed mode while Fig. 9 shows different simulation results for different values of $R_{D}$ for super-synchronous speed mode. It is evident that the model of Fig. 6 compares favorably with the simulation results of Fig. 8. There is no doubt also that the model of Fig. 7 compares favorably with the simulation results of Fig. 9.

If the desire is to have the DC-Link fault voltage almost damped out even before the fault is cleared, an RD much more than L should be designed into the system. In a similar manner, if it is desired to have a DC-Link fault voltage growth but less than the value that can excite a protective system before the fault is cleared, an $R_{D}$ less than but not much less than $\alpha L$ should be the choice. If however, $R_{D}$ much less than $\alpha L / 2$ is inserted in the minor loop of the inner current control, the tendency is that $v_{D C f}$ might grow rapidly and may excite the protective system even before the fault is cleared similar to what obtains in an undamped control strategy. 
DC Link fault voltage (V)

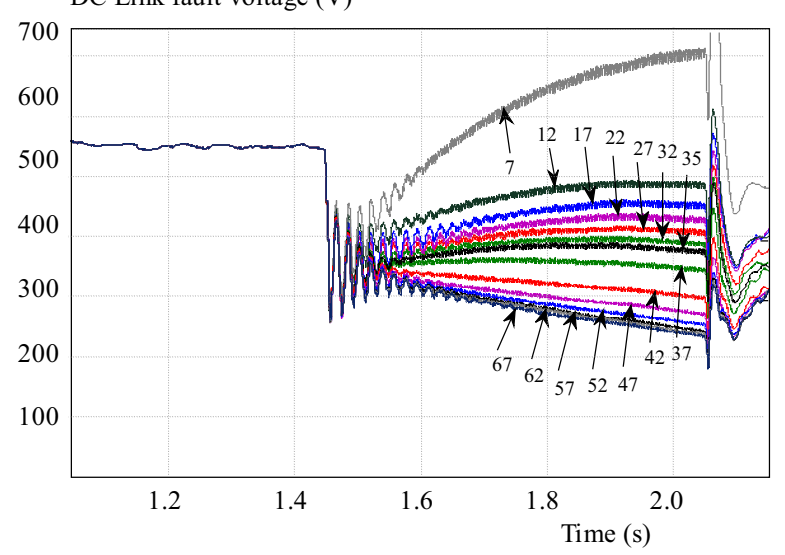

Fig. 8. Simulation results for DC-link fault voltage at different values of $R_{D}$ for sub-synchronous speed mode

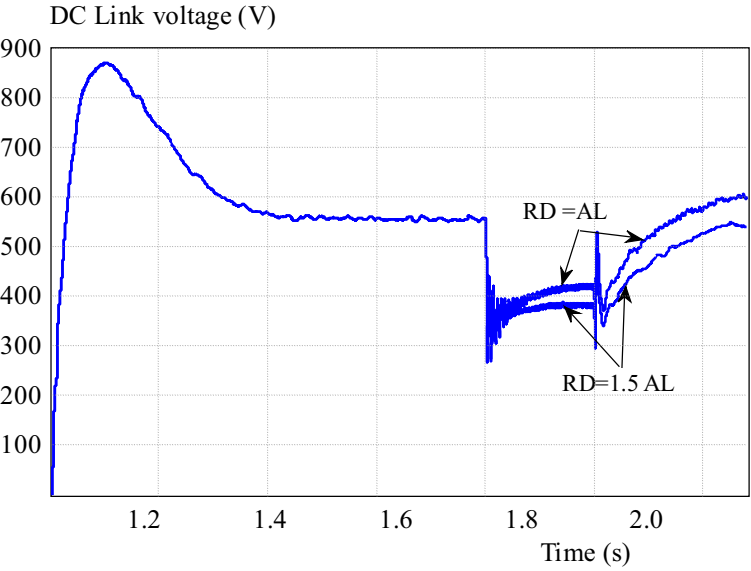

Fig. 10. DC-link voltage response to the active damping control strategy

Phase A rotor current (A)

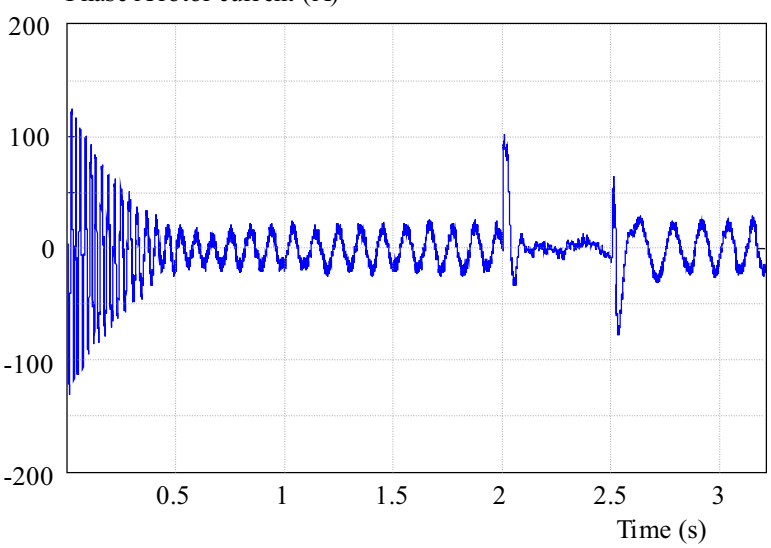

Fig. 12. The rotor current response to the control algorithm

\section{Proposed active damping criteria during grid fault}

Against the use of crowbar, DC-chopper, series dynamic resistor (SDR) and other power circuit protection strategies with inherent limitations which include non-fault ride-through capability, additional hardware requirements, losses from the crowbar, chopper, and SDR switching, a control circuit algorithm capable of inhibit-
DC Link fault voltage (V)

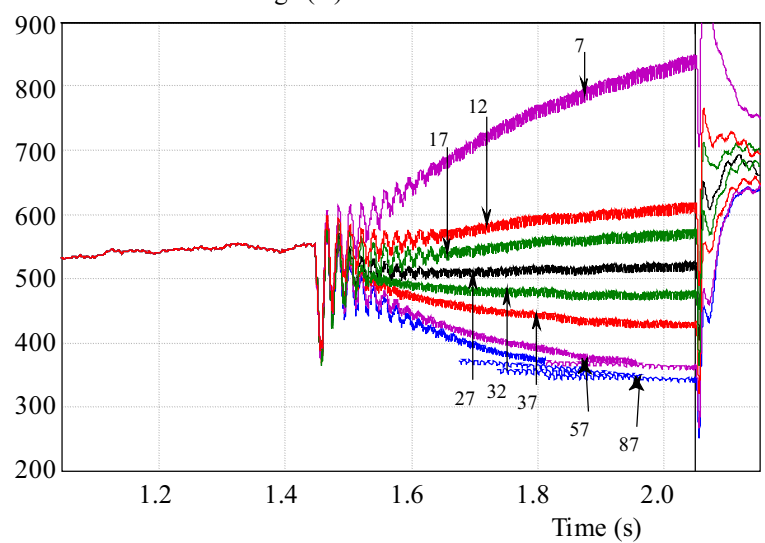

Fig. 9. Simulation results for DC - link fault voltage at different values of $R_{D}$ for super-synchronous speed mode

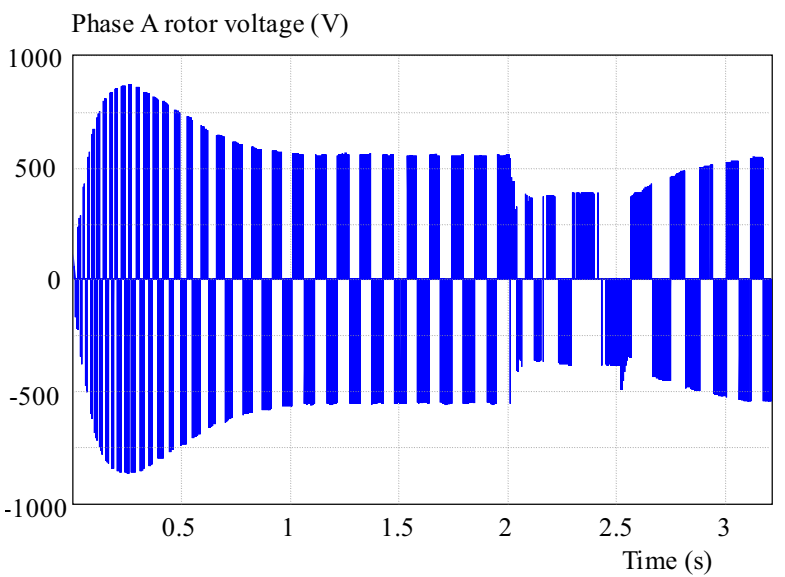

Fig. 11. Phase 'A' rotor voltage response to active damping control

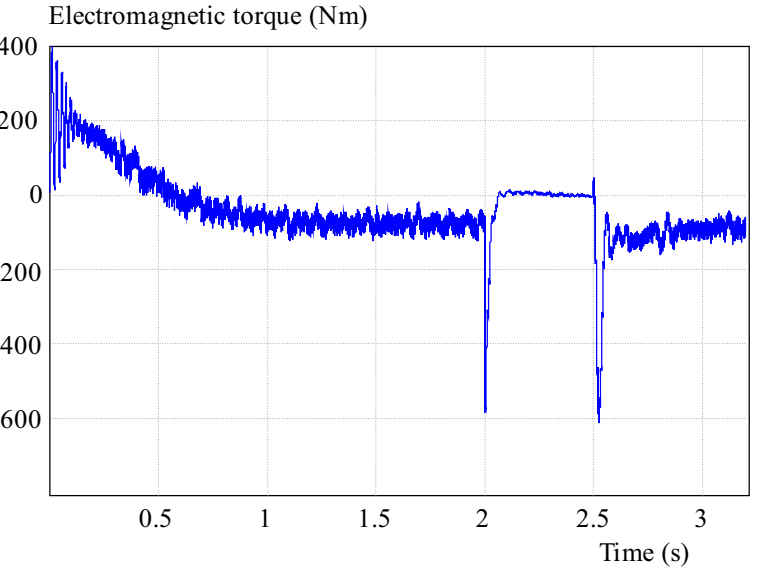

Fig. 13. Electromagnetic torque response

ing the phenomenal rise in the DC-link voltage whose dynamics has direct influence on the characteristics of the rotor voltage especially during grid faults is here proposed. In this protection algorithm, no additional sensors or additional control design is demanded. A minor loop in the existing inner-current control loop utilizing the same current sensor meant for the current control is only the requirement. This control strategy only at the GSC is applied in the control of the DFIG and converters during 


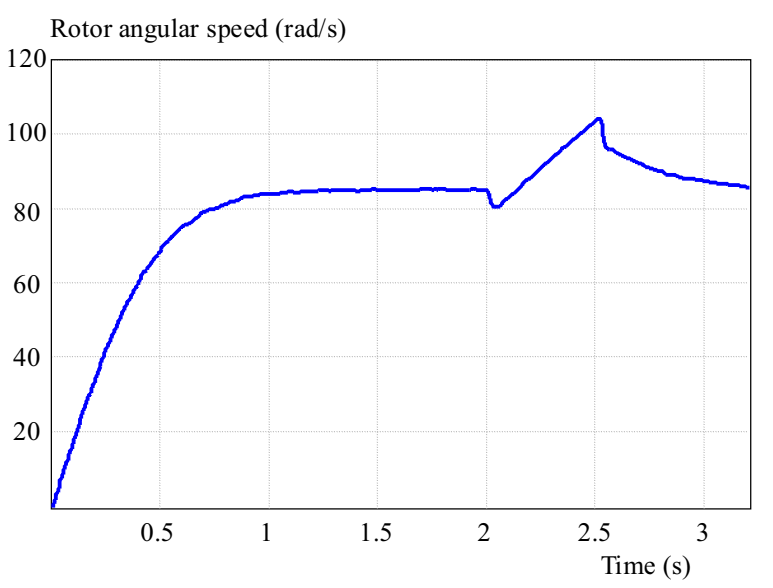

Fig. 14. Rotor angular speed

sub-synchronous and super-synchronous speeds of operations.

\subsection{Sub - synchronous speed mode}

A three-phase short-circuit to ground fault is introduced at $t=2 \mathrm{~s}$ and cleared at $t=2.5 \mathrm{~s}$. It is conventional to switch on the protective device once either the DC-link voltage or the rotor current reaches a preset value. In this strategy, the active damping is also switched on at $t=2 \mathrm{~s}$ and switched off at $t=2.5 \mathrm{~s}$. By iterative technique, an $R_{\text {Dopt }}=3 \alpha L / 2$ or 40.5 is determined. Figure 10 is the resulting DC-link voltage showing two traces one for $R_{D}=\alpha L$ and the other for $R_{D}=3 \alpha L / 2$. The phase ' $\mathrm{A}$ ' rotor voltage is shown in Fig. 11; here it is seen that about seventy per cent of the rotor voltage nominal value is maintained through the fault duration.

Shown in Fig. 12 is the phase 'A' rotor current where it is observed that some value of the rotor current still flow within the fault. Figure 13 is the electromagnetic torque while the rotor angular speed is displayed in Fig. 14.

\subsection{Super-synchronous speed mode}

Here, a three-phase short-circuit to ground fault is also introduced at $t=2 \mathrm{~s}$ and cleared at $t=2.5 \mathrm{~s}$. In this strategy, the active damping is switched on at close to 130 per cent of DC-link voltage and this occurs at

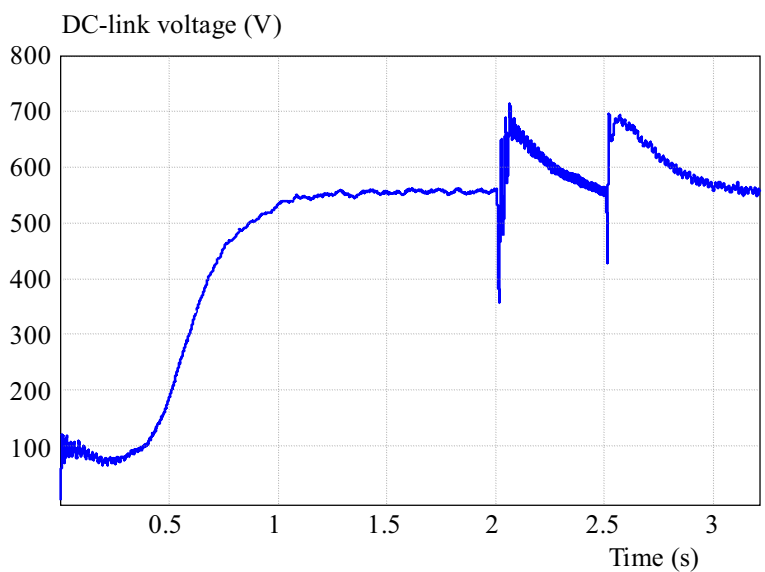

Fig. 15. DC-link voltage response to the first switching strategy of the active damping control $t=2.06 \mathrm{~s}$ and is switched off at $t=2.5 \mathrm{~s}$. An $R_{\text {Dopt }}=\alpha L$ or 27 is determined for the super-synchronous speed fault condition. Figure 15 is the resulting DC-link voltage when the damping is switched in at $2.06 \mathrm{~s}$ while Fig. 16 is the resulting DC-link voltage when the damping is switched in at $t=2 \mathrm{~s}$. The phase ' $\mathrm{A}$ ' rotor voltage is shown in Fig. 17 for the first switching strategy while Fig. 18 is the rotor voltage for the second switching strategy. Shown in Fig. 19 is the phase ' $\mathrm{A}$ ' rotor current where it is observed that more than fifty per cent of the rotor current flows after few periods of the fault occurrence. Figure 20 is the electromagnetic torque while the rotor angular speed is displayed in Fig. 21.

\section{Conclusions}

Active damping of a first-order single inductive filter connected between the grid and grid-side converter in a DFIG variable speed wind energy system has been presented. In addition to damping out transient oscillations particularly at the inception and at the end of faults, fault signals, for instance the DC-link voltage, are maintained to a level not capable of exciting protective schemes. The simulation tests were performed for faults during the subsynchronous and super-synchronous speeds operation of DFIG variable speed wind turbine. Owing to the direct influence of the DC-link voltage dynamics on the rotor voltage, limiting the value of DC-link voltage during faults also entails limiting the value of the rotor voltage.

In furtherance to the benefits of the dynamics of active damping criteria, a model that can be used to predict the variation of DC-link voltage and hence the rotor voltage in a DFIG variable speed wind turbine during grid fault has also been generated. For different values of damping resistor $\mathrm{RD}$ in relation to the product of the inner loop control bandwidth and the filter inductance, different simulation runs were made. The model results so obtained compare favorably with the simulation results. At the optimal value of the damping resistor $R_{\text {Dopt }}$, the DClink voltage maintains constant value through the period of the fault as against the usual phenomenal rise both for the model and simulation results and hence provides

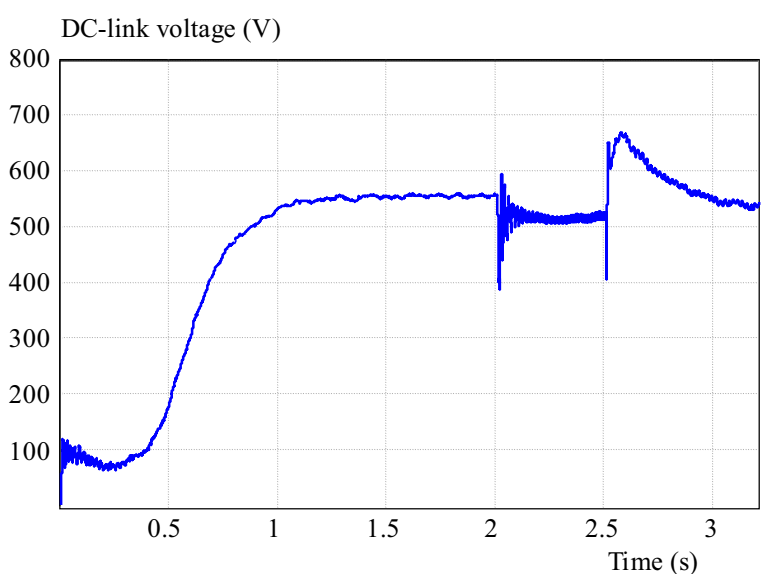

Fig. 16. DC-link voltage response to the second switching strategy of the active damping control 


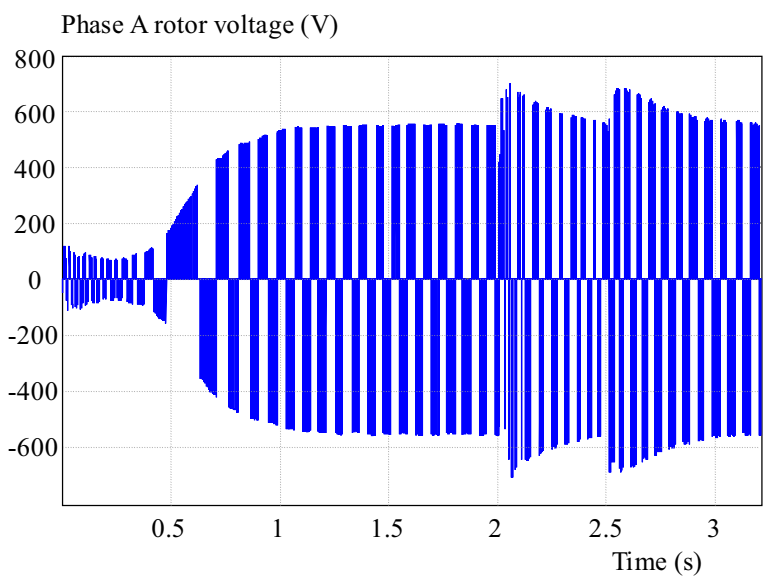

Fig. 17. Phase 'A' rotor voltage response to the first switching strategy

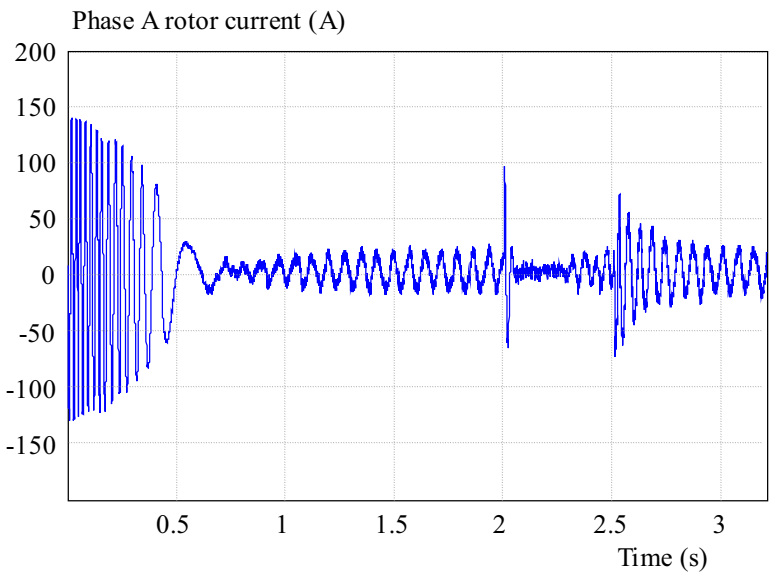

Fig. 19. The rotor current response to the active damping control

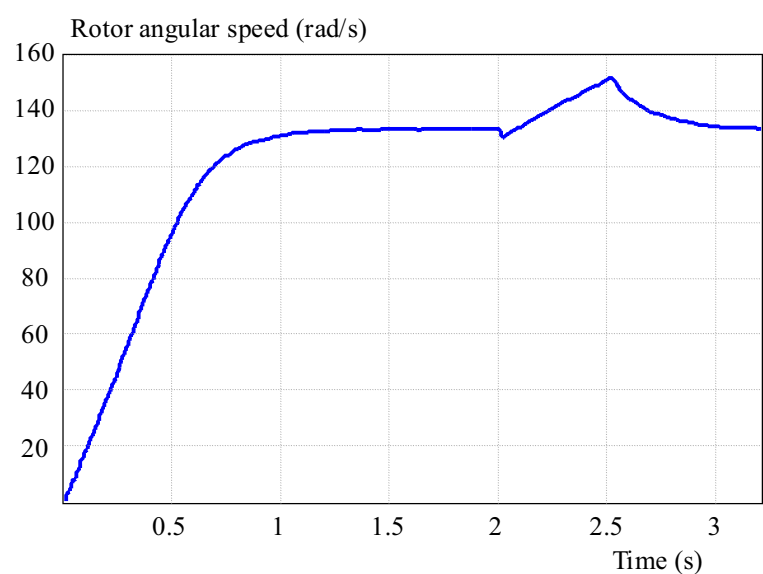

Fig. 21. Rotor angular speed

for a ride-through capability of the wind turbine system during fault.

As against the conventional practice of extra circuit dependent protective scenarios such as crowbar, DC chopper, and SDR none of which is a good candidate for ridethrough capability either singly deployed or in a combined approach, it has been confirmed through simulation re-

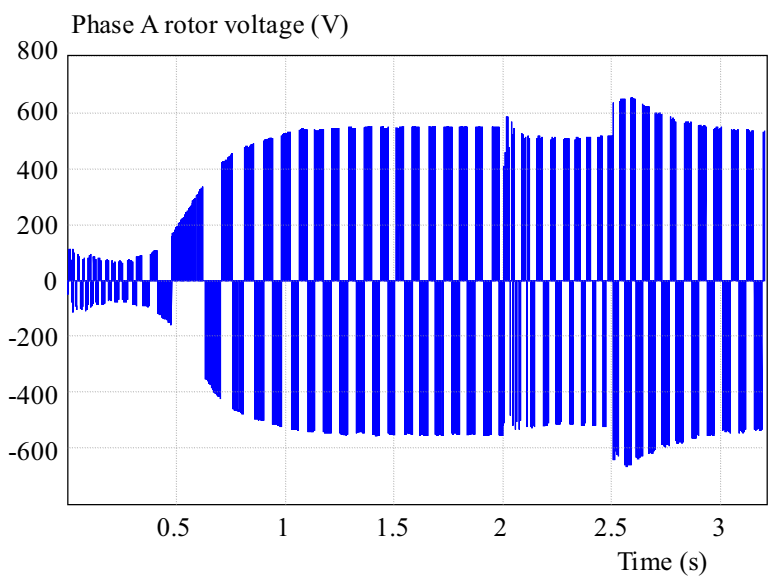

Fig. 18. Phase 'A' rotor voltage response to the second switching strategy

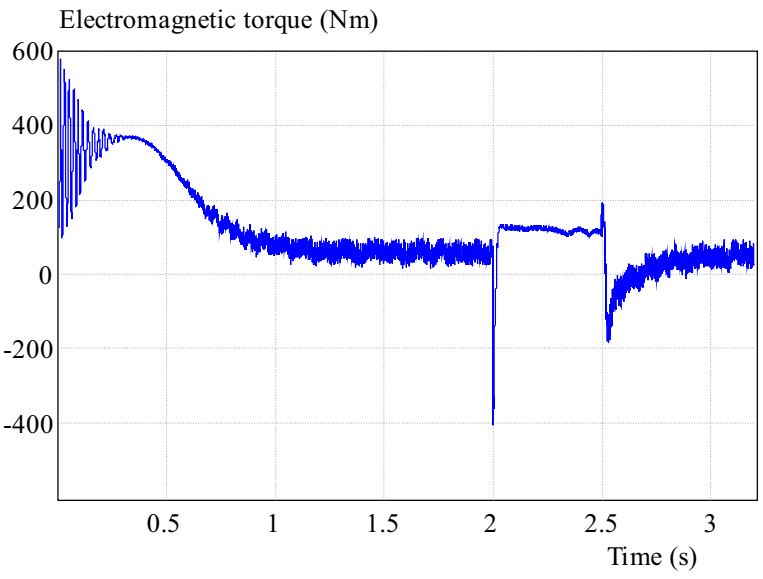

Fig. 20. Electromagnetic torque response

sults that the active damping control criteria promises to be a better control scheme for the future. In summary, the additional control loops at the d-q current control loops of the GSC provided the control opportunity for the grid damping possibility and to have the wind turbine connected to the grid in times of grid fault. Future work shall be devoted to committing the analysis results to experimental verifications.

\section{REFERENCES}

[1] J. Lettl, J. Bauer and L. Linhart, "Comparison of Deferent Filter Types for Grid Connected Inverter", PIERS Proceedings, Marrakesh, MOROCCO, March 20-23 2011, pp. 1426-1429.

[2] P. A. Dahono, "A Method to Damp Oscillations on the Input LC Filter of Current-Type AC-DC PWM Converters by Using a Virtual Resistor", IEICE/IEEE INTELEC (2003), 757-761.

[3] K. Hyosung and K. S. Seung, "A Novel Filter Design for Output LC Filters of PWM Inverters" Journal of Power Electronics, 2011, vol. 11 , no. 1 , pp. $74-81$.

[4] A. Raheel, J. Mohsin, W. Adeel, N. Asad, A. Arifeen and H. M. Mazhar, "Design and Analysis of Second Order Passive Filters for Grid Connected Inverter with Series and Parallel Damping Resistors", Indian Journal of Science and Technology, 2016, vol. 9, no. $21,5.1 .2017$. 
[5] B. G. Cho and S. K. Sul, "LCL Filter Design for Grid-connected Voltage-source Converters High Power Systems IEEE", Trans. Industrial Applications, 2012 pp. 1548-1555.

[6] Y Tang, P. C. Loh, P. F. Wang, H. Choo and F. Gao, "Exploring Inherent Damping Characteristics of LCL-Filters for Three-Phase Grid-Connected Voltage Source Inverters" IEEE Trans. Power Electron., 2012, vol. 27, no. 3 pp. 1433-1443.

[7] S. G. Parker, B. P. McGrath and D. G. Holmes, "Regions of Active Damping Control for LCL Filters" IEEE Trans. Ind. Applicat., 2012, -IPCC-463.

[8] B. C. Parikshith and J. Vinod, "Higher Order Output Filter Design for Grid Connected Power Converters" Fifteenth National Power Systems Conference (NPSC), IIT Bombay, (2008), pp.614-619.

[9] L. Sangmin and C. Jaeho, "LCL Filter Design for Grid Connected NPC Type Three-Level Inverter", International Journal of Renewable Energy Research, 2015, vol. 5, no. 1, pp. 45-53.

[10] W. Christian, D. -jorg and W. F. Friedrich, "Active Damping of LCL-Filter Resonance based on Virtual Resistor for PWM Rectifiers - Stability Analysis with Different Filter Parameters", IEEE Annual Power Electronics Specialists Conference, July 2008, pp. 1-8.

[11] X. Wang, F. LOH and P. C. Blaabjerg, "Virtual RC Damping of LCL-Filtered Voltage Source Converters with Extended Selective Harmonic Compensation" IEEE Transactions on Power Electronics, 2015, vol. 30, no. 9, pp. 4726-4737.

[12] G. Thoma, P. Sonia and G. Johan, "Assessment of Grid-Side Filters for Three-Phase Current-Source Inverter" PV Systems, 2016, vol. 11, no. 6 .

[13] J. Dannehl, F. W. Fuchs, S. Hansen and P. B. Thogersen, "Investigation of Active Damping Approaches for PI-Based Current Control of Grid-Connected Pulse Width Modulation Converters with LCL Filters", IEEE Trans. Industrial Applications, 2010, vol. 46, pp. 1509-1517.

[14] B. G. Cho and S. K. Sul, "LCL Filter Design for Grid-Connected Voltage-Source Converters High Power Systems", IEEE Trans. Industrial Applications, 2012, pp. 1548-1555.

[15] J. MORREN, "Grid Support by Power Electronic Converters of Distributed Generation Units" PhD Thesis, Delft University of Technology, (TU-Delft), the Netherlands, 2006.

[16] M. Liserre, F. Blaabjerg and S. Hansen, "Design and Control of an LCL-Filter-Based Three-Phase Active Rectifier", IEEE. Trans. Ind. Applications, 2005, vol. 41 no. 5, pp. 1281-1291.

[17] A. Papavasiliou, S. MANIAS, S. Papathanassiou and G. Demetriadis, "Current Control of a Voltage Source Inverter Connected to the Grid via lcl Filter", 2007, pp. 2379-2384.

[18] J. Dannehl, M. Liserre and F. W. Fuchs, "Filter-Based Active Damping of Voltage Source Converters with LCL Filter", IEEE Trans. Ind. Electron., 2011, vol. 58, no. 8, pp. 3623-3633.

[19] E. Twining and D. G. Holmes, "Grid Current Regulation of a Three-Phase Voltage Source Inverter with an LCL Input Filter", IEEE Trans. Power Electron., 2003, vol. 18 no. 3, pp. 888-895.

[20] R. Pena-alzola, M. Liserre, F. Blaabjerg, R. Sebastian, J. Dannehl and F. W. Fuchs, "Systematic Design of the Lead-Lag Network Method for Active Damping LCL-Filter Based Three Phase Converters", Industrial Informatics, IEEE Transactions on, 2014, vol. 10, no. 1, pp. 43-52.

[21] D. Ricchiuto, M. Liserre, T. Kerekes, R. Teodorescu and F. Blaabjerg, "Robustness Analysis of Active Damping Methods for an Inverter Connected to the Grid with an LCL-Filter", Energy Conversion Congress and Exposition (ECCE), 2011 IEEE, pp. 2028-2035.

[22] M. Liserre, A. D. Aquila and F. Blaabjerg, "Genetic Algorithm-Based Design of the Active Damping for an LCL-Filter
Three-Phase Active Rectifier", Power Electronics, IEEE Transactions on, 2004, vol. 19, no. 1, pp. 76-86.

23] L. NEE and H-P. Harnefors, "Model-Based Current Control of AC Machines Using the Internal Model Control Method", IEEE Trans. Ind. Applicat., 1998, vol. 34, pp. 133-141.

24] T. Sun, "Power Quality of Grid-Connected Wind Turbines with DFIG and their Interaction with the Grid", 2004, PhD Thesis, Aalborg Univeristy, Denmark.

Received 6 October 2016

Cajethan Nwosu, PhD, was born 1st October 1967. He obtained the BEng, MEng, and PhD degrees in electrical engineering from the University of Nigeria, Nsukka in 1994, 2004, and 2015 respectively. In 2007, he undertook a three months pre-doctoral research on Wind/Solar Hybrid Power System and Renewable Energy Resources at the University of Technology, Delft (TU-Delft), the Netherlands. Since 2005, he has been with the Department of Electrical Engineering, University of Nigeria, Nsukka, where he is currently a Senior Lecturer. He had written two books and had published over thirty articles both in local and international journals. He is an executive member of Nigerian Institution of Electrical and Electronic Engineers (NIEEE), Nsukka chapter. He is a member of Power Electronics Society of Institution of Electrical and Electronic Engineering (PES IEEE). He is an editorial board member World Science Journal of Engineering Applications. His areas of research interest include power electronic converters, electrical drives and renewable energy technologies.

Cosmas Ogbuka, PhD, was born in Umuna Nigeria on 1st April, 1981. He received his BEng (First Class Honors), MEng (Distinction) and PhD in 2004, 2009 and 2014 respectively in the Department of Electrical Engineering University of Nigeria, Nsukka, where he presently works as a lecturer I. His research interests are in adjustable speed drives of electrical machines: (DC and AC electric machine torque/speed control with converters and inverters), electric machines and power electronics. He has published both locally and internationally and attended conferences within and outside Nigeria. He is a member of Nigerian Society of Engineers (NSE), Nigerian Institution of Electrical Engineers (NIEEE), International Association of Engineers (IAENG) and is registered by the Council for the Regulation of Engineering in Nigeria (COREN). He is presently on a postdoctoral research visit at the Chair of Electrical Drives and Actuators (EAA) Universität der Bundeswehr München, Germany with professor Dr-Ing Dieter Gerling.

Stephen Ejiofor Oti, PhD, was born in 1974. He obtained the BEng, MEng, and $\mathrm{PhD}$ degrees in electrical engineering from the University of Nigeria, Nsukka in 1998, 2006, and 2014 respectively. In 2000, he was engaged as senior mathematics teacher in Special Science School, Nsukka from where he joined the Electrical Engineering Department, UNN as a principal technical officer and was later in 2007 converted to the lecturing cadre in the same department. He is a member of Nigerian Society of Engineers (NSE) and is also a registered member of Council for the Regulation of Engineering in Nigeria (COREN). His research areas include machine modeling, thermal modeling, power and energy systems modeling and simulations. 